\title{
Paddock scale modelling to assess effectiveness of agricultural management practice in improving water quality in the Great Barrier Reef Catchments
}

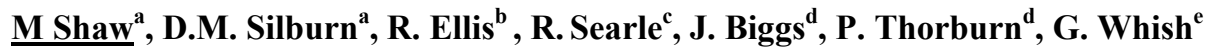 \\ ${ }^{a}$ Department of Natural Resources and Mines, Queensland \\ Email: Melanie.Shaw@dnrm.qld.gov.au \\ ${ }^{b}$ Department of Science Information Technology Innovation and the Arts, Queensland \\ ${ }^{c}$ CSIRO Land and Water \\ ${ }^{d}$ CSIRO Ecosystem Sciences \\ ${ }^{e}$ Department of Agriculture Fisheries and Forestry, Queensland
}

\begin{abstract}
Agriculture in the catchment areas adjacent to the World Heritage listed Great Barrier Reef (GBR) Marine Park generates pollutants that are a concern for the health of the Reef. Under the Paddock to Reef Integrated Monitoring, Modelling and Reporting program (P2R) of the Reef Plan, the impacts of improved agricultural management practices on water quality entering the GBR are modelled to evaluate the effectiveness of Government water quality improvement policies. The Source Catchments modelling framework estimates loads of pollutants entering the GBR lagoon from rivers. However, Source Catchments does not have the capacity to represent the collection of management practices available to farmers that affect water quality in runoff and drainage at a paddock scale. Therefore, paddock scale agricultural systems models were used to demonstrate the effects of management practice adoption and to provide input to the catchment scale models. Paddock scale models were used because they represent a level of process detail compatible with the management practice investments and implementation on-ground.
\end{abstract}

A fit-for-purpose modelling approach was used, where the paddock model most suited to a given land use and/or water quality pollutant was applied. Three one-dimensional agricultural systems models were employed; HowLeaky in grains, APSIM in sugarcane with HowLeaky post-processing for herbicides and phosphorous and GRASP in grazing lands. These models share similar soil water balance, ground cover and runoff sub-models. However, they vary in the level of detail, particularly in terms of representing crop growth and in the processes considered, such as pesticide degradation and export.

In grains and sugarcane cropping, the pollutant time-series (e.g. load per day per unit area) in the Source Catchments models was replaced with an output time-series from HowLeaky or APSIM for each soil-climate spatial combination. Management practices were grouped into systems classed as A, B, C or D. The proportion of each of these management systems contributing to the modelled loads was adjusted to reflect data on the prevalence of adoption of improved management practices in the GBR catchment.

In grazing lands, GRASP pasture utilisation and ground cover time-series outputs were interrogated to derive relationships between changes in grazing system management and changes in the USLE C-factors. The USLE is used to predict hillslope erosion in the Source Catchments model. Scaling indices derived from GRASP outputs were used to adjust the USLE C-factors applied in Source Catchments where management practices had changed.

The P2R program has demonstrated the effectiveness of linking paddock scale models or emergent models derived from them with catchment scale models. This has enabled detailed management options to be simulated to investigate broad scale water quality impacts of the adoption of improved agricultural practices.

Keywords: $\quad$ Paddock to Reef, water balance modelling, HowLeaky, APSIM, GRASP 


\section{INTRODUCTION}

Farmers face daily decisions about management of their land. These decisions can have implications not only for the productivity of a property, but also for the quality of water that leaves the property through runoff and drainage. Agricultural runoff has been identified as a threat to water quality entering the world heritage listed Great Barrier Reef (GBR) lagoon. In 2003, the Australian and Queensland governments put in place the Reef Water Quality Protection Plan (Reef Plan) to address the issue of pollutants entering the GBR through agricultural practices. Reef Plan was updated in 2009 and again recently in 2013 (Anon 2009, 2013). Reef Plan sets targets for the improvement of water quality entering the GBR lagoon; namely a reduction in nutrient, pesticide and sediment loads. Reef Plan is supported by a funding package which provides assistance to farmers and land managers in GBR catchments to adopt management practices that reduce runoff of nutrients, pesticides and sediment from agricultural lands.

The integrated paddock to reef monitoring, modelling and reporting program (P2R) has been established to evaluate the progress being made towards achieving the load reduction targets set in Reef Plan (Carroll et al., 2012). Catchment scale modelling has been implemented using the Source Catchments framework (Kelley and O'Brien, 2012) for each of the six natural resource management (NRM) regions within the GBR catchment (see Ellis and Searle, 2013). Within Source Catchments, the ability to represent the effects of complex management options on water quality of pollutants such as dissolved inorganic nitrogen or pesticides is limited to the application of a single mean concentration to all runoff events. In contrast, agricultural systems models allow explicit representation of the collection of management options available to a farmer such as crop rotations and planting, tillage and nutrient and herbicide applications. Importantly, the ability to simulate management practices on a daily time step means that interactions between the timing of management options and climate conditions can be taken into account. Agricultural systems models have therefore been used to predict changes resulting from improved management systems. The outputs from these paddock scale models, or emergent relationships between management practice and environmental outcomes derived from them, were used to provide input to pollutant generation in the catchment scale models.

Along with the paddock modelling program, paddock scale monitoring sites were established through the P2R program. These sites provided observations of benefits to water quality following implementation of practices for comparison to the modelling and were an important point of truth for model validation and parameterisation.

Agricultural systems models have been used to extrapolate findings from experimental sites for many years. This paper presents an extension of this where outputs from paddock scale simulations of grains, sugarcane and grazing land uses were used to generate pollutants for a catchment scale modelling project that spans an area approximately $423000 \mathrm{~km}^{2}$, or almost twice the size of the United Kingdom. The simulations serve dual purposes; they provide feedback on progress towards load reduction targets for pollutants entering the GBR lagoon by adoption of improved management practices and they facilitate investigation of a wide range of management options to prioritise future investment.

\section{MODELLING MATRIX}

A fit-for-purpose modelling approach was used where the paddock model most suited to a given land use and/or pollutant was applied. Implementation of the best available model was an important component to satisfying the quality assurance aims of the P2R program. The framework that enables the import of paddock modelling results into Source Catchments has been custom developed for the P2R program and is described in Ellis and Searle (2013). Three one-dimensional agricultural water balance models were employed; HowLeaky in grains, APSIM in sugarcane with HowLeaky post-processing for herbicides and phosphorous and GRASP in grazing lands. These models share similar soil water balance, ground cover and runoff submodels. However, they vary in the level of detail, particularly in terms of representing crops and in the processes considered, such as pesticide degradation, nitrogen cycle or pasture utilisation by cattle.

HowLeaky (Rattray et al., 2004; Robinson et al., 2010) was chosen for modelling grain cropping. HowLeaky is derived from PERFECT (Littleboy et al., 1992) with some enhancements (described by Robinson et al., 2010). HowLeaky was chosen for grain cropping lands because (a) PERFECT and HowLeaky have been extensively validated with hydrology data for cropping systems in Queensland for runoff, erosion and the movement of nutrients attached to sediments (e.g. Littleboy et al., 1992; Chamberlain et al., 2009; Freebairn et al., 2009) (b) HowLeaky predicts pesticide mass balance and runoff losses (Shaw et al., 2011) and (c) has been modified to model dissolved and particulate phosphorus in runoff (Robinson et al., 2011). The HowLeaky functions were also run on the APSIM water balance outputs for sugarcane to model phosphorus and herbicides. 
APSIM (Keating et al., 2003), which has a water balance module also derived from PERFECT, was chosen for modelling sugar cane because (a) it has been used extensively for that system including major field studies (b) it has a complete soil nitrogen $(\mathrm{N})$ and carbon $(\mathrm{C})$ balance and fertiliser management module, (c) can model dissolved $\mathrm{N}$ losses to runoff and deep drainage, and (d) has been validated for comprehensive data of these processes (e.g. Thorburn et al., 2005, 2011).

Modelling of grazing systems was achieved using the pasture growth model GRASP (McKeon et al., 2000; Rickert et al., 2000). It was developed to simulate aspects of grass production and to predict soil water, pasture growth and animal intake for semi-arid and tropical grasslands. GRASP has been used to evaluate a wide range of grazing management issues from assessing safe carrying capacities and land degradation, to evaluating the impacts of climate variability and management practices on extensive grazing lands.

\section{MODELLING CROPPING}

\subsection{Identifying representative scenarios}

Land use maps for the year 2009 produced by the Queensland Land Use Mapping Program (QLUMP) (DSITIA, 2012) were used to define the extent of cropping lands in the GBR catchments. Land use categories represented in the QLUMP mapping were reclassified into 13 categories considered to be representative of the GBR catchment. All broad acre cropping land classes (approx. $1400 \mathrm{~km}^{2}$ ) were classed as either 'sugarcane' or 'other cropping'. Areas mapped as 'other cropping' were modelled as a rotation of key crops that were identified following input from agricultural extension staff from the grains industry. The HowLeaky modelling approach described here applies directly to 'other cropping' while a similar, but modified, approach in APSIM was applied to sugarcane.

A common approach to extrapolating agricultural systems models spatially is to assign parameters from a few well studied sites to locations considered most similar. While there is merit in this approach given that model parameters have been measured and results can be validated for a specific site, it was not applied for 'other cropping' scenarios. Rather than selecting a few representative scenarios, an automated approach was adopted which linked a spatial intersection between climate, soil properties and topography information with a database of parameters to build representative scenarios. Approximately 6120 unique scenarios were defined for 'other cropping' alone. This has resulted in a spatially-intense modelling capability that matches the variability in land use, soil and climate conditions in the GBR catchment.

A daily climate file specifying inputs including rainfall, radiation and temperature was sourced from an interpolated gridded dataset available at 0.05 degree coverage from the SILO database (http://www.longpaddock.qld.gov.au/silo/). Use of interpolated climate data meant that the original measured data from climate stations was not included in the modelling, but allowed for a high level of spatial intensity in representation of climatic differences across the GBR catchment.

Soils in the GBR catchment were grouped based on properties considered important for predicting hydrology. At the highest level of grouping, functional orders were developed based on factors including Australian Soil Classification, infiltration/runoff potential and surface condition (sealing, crusting, etc.), soil depth, clay fraction and sodicity. Functional orders were further split into groups based on permeability and the depth of the A and B horizons. A total of 341 soils groups were identified in the GBR catchment (Robinson et al., 2012). These soils groups were mapped and parameters derived based on the Australian Soil Resource Information System Database (ASRIS, Brough et al., 2006). Within ASRIS, soil properties were predicted at a given location by pedotransfer functions from measured site data. Parameters assigned to a soil group represented the average of all ASRIS results returned for that group in the GBR catchment, with filtering applied for spurious or unrealistic values. An important aspect of this approach was that it provided datasets for areas where no site measurements were available while avoiding the subjectivity associated with selecting a 'similar' soil.

Parameters related to site topography and the clay plus silt fractions based on location were determined for each simulation so that a unique parameter input was generated. These parameters included slope derived from digital elevation mapping, the rill to interrill ratio which was calculated following determination of the slope and slope length, and the clay plus silt fraction of the soil used to simulate delivery of fine particles to streams. 


\subsection{Representing management options}

Management practice frameworks have been developed for the sugarcane and grains industries in each of the NRM regions of the GBR catchment. Management practices have been grouped to whole-of-farm systems where $\mathrm{A}$ is aspirational practices, $\mathrm{B}$ is industry best practice standard, $\mathrm{C}$ is common practices and $\mathrm{D}$ practices are those deemed unacceptable in terms of the water quality outcomes (Carroll et al., 2012). While each landholder will implement a collection of practices that are unique to the needs and constraints of their property, the ABCD framework identifies major differences in management systems that have an impact on water quality leaving a paddock. These practices are grouped into those that primarily affect soil/sediment transport (such as tillage and stubble retention), nutrient application practices and herbicide application practices. An example of the key aspects defining ABCD systems for soil management practices in the Fitzroy region for 'other cropping' is shown in Table 1. Each unique spatial scenario modelled in HowLeaky or APSIM was also modelled as an A, B, C and D level of practice management.

Table 1. Characteristics defining ABCD management systems for 'other cropping' in the Fitzroy region of the GBR catchment

\begin{tabular}{llcll}
\hline Class & Crops & $\begin{array}{c}\text { Crops per } \\
\text { 10yrs }\end{array}$ & Tillage/Traffic & Tillage operations \\
\hline A & $\begin{array}{l}\text { Sorghum, Wheat, } \\
\text { Chickpeas } \\
\text { Sorghum, Wheat, }\end{array}$ & 9 & $\begin{array}{l}\text { Zero till controlled } \\
\text { traffic } \\
\text { Cero till, random } \\
\text { wheel traffic } \\
\text { Chickpeas }\end{array}$ & Direct drill planting \\
C & $\begin{array}{l}\text { Sorghum, Wheat, } \\
\text { Chickpeas } \\
\text { Sorghum, Wheat }\end{array}$ & 7 & Direct drill planting \\
D & 7 & Conventional till & $\begin{array}{l}\text { Multi-tyned planters, scarifiers, } \\
\text { chisel plough after harvest }\end{array}$ \\
\hline
\end{tabular}

Each of the cropping model runs generated a daily time series of load exports on an area basis for each of the water quality pollutants (e.g. load per day per unit area) for use in the catchment modelling (see Ellis and Searle, 2013). Off-site sediment transport from selected spatial scenarios within the Fitzroy region of the GBR catchment is shown in Figure 1. Not only are there differences in the magnitude of sediment loss for one management class across the spatial scenarios, but also in the relative differences between those management classes. This demonstrates the benefit of generating spatially explicit scenarios rather than applying the results from several well studied sites when working across scales as large as the GBR catchment.

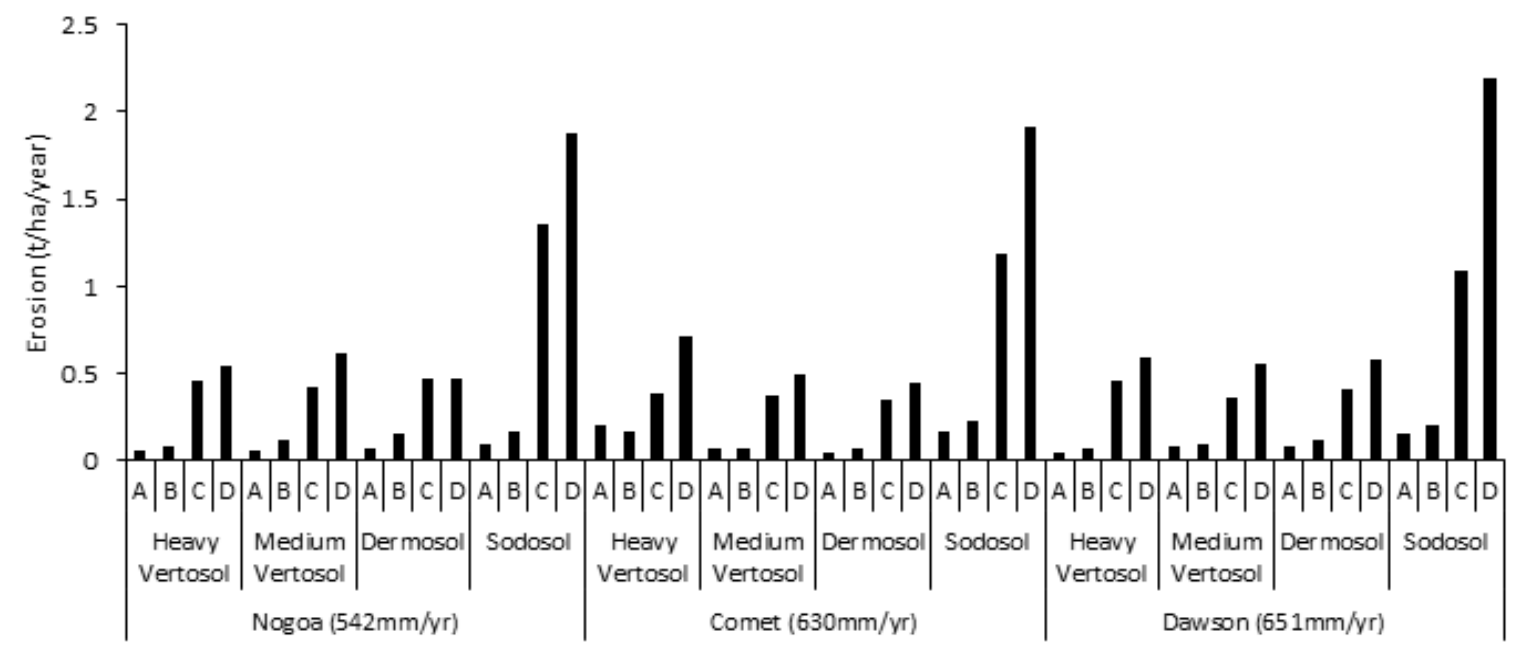

Figure 1. Example of relative losses of sediment from $A, B, C$ and $D$ levels of management for grains cropping on selected soils and climates from three river basins in the Fitzroy region of the GBR catchment

Further, it shows that knowledge about where in the catchment the different practices are occurring is advantageous in predicting water quality outcomes. The assignment of management practices spatially was able to be done at a property scale where that information was available. In many cases, privacy issues prevented management practice adoption data being shared at a property scale. The modelling framework also accommodated broader scale assessments of the proportion of an area, typically a modelling subcatchment, under $\mathrm{A}, \mathrm{B}, \mathrm{C}$ or $\mathrm{D}$ management. In these cases, the management practices were evenly 
distributed across all of the spatial combinations within the sub-catchment. This approach avoided the need to incorrectly assign the management practices to a specific scenario which could bias outputs. For example, if D management practices were assigned to scenarios with high slope and high erosivity, the disadvantage of that unacceptable practice would be overstated in the final catchment model output.

\section{MODELLING GRAZING}

\subsection{Identifying representative scenarios}

Given the extensive areas (approx. $28500 \mathrm{~km}^{2}$ ) under grazing in the GBR catchment, it was not feasible to run individual paddock models for all combinations of soil, vegetation, climate and topography. Rather, modelling was conducted over a range of representative land types and climates to identify emergent relationships which could be applied in the Source Catchments model (Whish 2012). Areas of the GBR catchment under grazing land use were identified by the 2009 Queensland land use mapping (QLUMP). Within this extent, land types (Whish 2011) were identified and classified into levels of productivity. Six land types representing five levels of productivity (Table 2) were selected for modelling in GRASP. Land types were modelled at 10 climate stations to capture the north-south variability in rainfall (annual, seasonal, intensity) and the range in humidity and vapour pressure deficit across the eastwest gradient in the GBR catchment.

\subsection{Representing management options}

For each of the climate/land type scenarios identified, 15 pasture utilisation rates were modelled using GRASP to represent the impacts of management options ranging from no grazing, zero utilisation through to severe overgrazing (1000 head/ha). Linear interpolation between outputs from the modelled utilisation rates provided results for all possible stocking scenarios. As was the case for cropping lands, management practice systems in grazing were defined by an ABCD framework (see section 3.2 for the definition of classes). The utilisation rates appropriate to each level of management for each of the modelled land types was nominated by grazing extension staff as were requirements for the maintenance of perennial pasture species. Criteria for average cover levels maintained through a simulation were also used to define the management classes since it was recognized that, for a given land type, climate would influence the outcomes of management decisions. The features of these cover-rainfall relationships were (1) cover declined under any management system when there was less rainfall, (2) cover was more similar between management steps in higher rainfall areas and span a wider range in drier locations (Figure 2). These features reflect the fact that cover is naturally

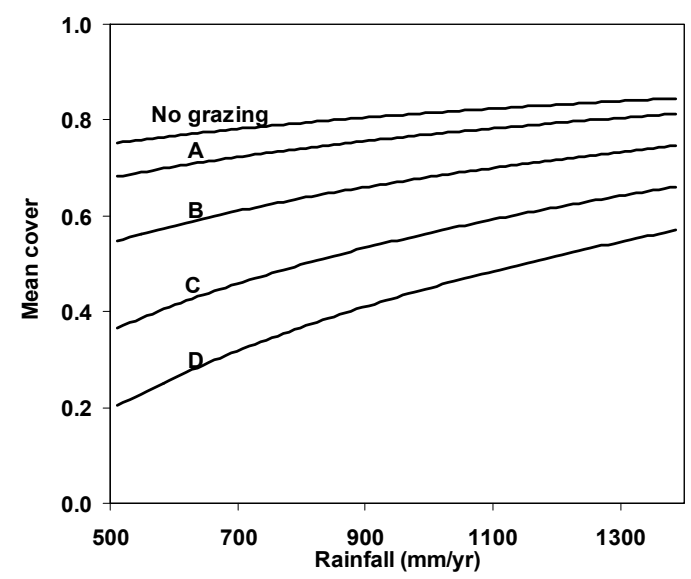

Figure 2. Average cover requirements for A, B, C and $\mathrm{D}$ levels of management across mean annual rainfall conditions

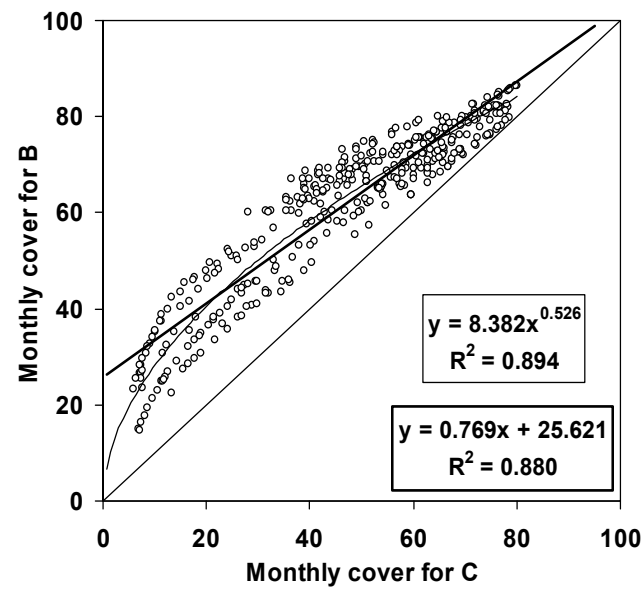

Figure 3. Relationship between $\mathrm{C}$ and $\mathrm{B}$ level management for Black basalt land type conditions 
lower in drier locations and highlight that there is greater possibility of improving cover in drier locations, whereas the cover in areas with high rainfall generally remains high irrespective of management practices. Once the appropriate utilisation rate scenario was assigned into A, B, C and D level management for each land-type and climate combination, the relationship between the management classes was investigated. Linear regression was conducted using average monthly cover for data pooled across climate stations (e.g. Figure 3). This allowed the factor increase in cover between each management step to be determined for a range of 'starting' cover levels. Importantly, derivation of linear relationships between cover at each management step, rather than a single change factor, avoided prediction of nonsensical results, such as $>$ $100 \%$ cover, in years when cover was already high. Linking of the management-cover relationships derived from the GRASP modelling to prediction of erosion through USLE in the Source Catchments models is described by Ellis and Searle (2013).

\section{CONCLUSIONS}

Linking detailed paddock models with a catchment scale model has been shown to provide an effective approach for assessing impacts of the adoption of improved land management practices. An important aspect to this modelling program has been collaboration between agencies with differing expertise which has enabled the best available models for a given land-use and pollutant to be applied. The P2R modelling program operates over a scale almost twice the size of the United Kingdom. However, across this large area there is spatially-intense representation of landscape and climatic conditions as well as paddock scale representation of management systems for cropping and grazing lands. Two approaches to incorporate the paddock scale modelling into Source Catchments models have been implemented within the P2R program; direct import of paddock scale outputs for cropping lands and the derivation of emergent relationships from detailed paddock modelling to scale erosion predictions. The validity of the P2R modelling approach has been evaluated by comparison of predictions to monitoring data in the GBR catchment (e.g. Dougall and Waters, 2013). The modelling outputs will continue to assess progress towards meeting reef water quality targets while providing a tool for investigation of management options at a paddock scale which will serve to improve water quality entering the iconic GBR ecosystem.

\section{ACKNOWLEDGEMENTS}

We wish to acknowledge the funding support from the Australian and Queensland governments under the Paddock to Reef Program.

\section{REFERENCES}

Anon. (2009, 2013). The State of Queensland and Commonwealth of Australia. Reef water quality protection plan; for catchments adjacent to the Great Barrier Reef World Heritage Area. Queensland Department of Premier and Cabinet, Brisbane, http://www.reefplan.qld.gov.au/.

Bastin, G., Scarth, P., Chewings, V., Sparrow, A., Denham, R., Schmidt, M., O’Reagain, P., Shephard, R., and Abbot, B., (2012). Separating grazing and rainfall effects at regional scale using remote sensing imagery: a dynamic reference cover method. Remote Sensing of Environment 121, 443-457.

Brough, D.M., Claridge, J., and Grundy, M.J. (2006). Soil and landscape attributes: A report on the creation of a soil and landscape information system for Queensland. Natural Resources, Mines \& Water, Brisbane, Australia.

Carroll, C., Waters, D., Vardy, S., Silburn, D.M., Attard, S., Thorburn, P,J., Davis, A.M., Halpin, N., Schmidt, M., Wilson, B., and Clark, A. (2012). A Paddock to reef monitoring and modelling framework for the Great Barrier Reef: Paddock and catchment component. Marine Pollution Bulletin 65, 136-149.

Chamberlain, T., Silburn, D.M., and Owens, J.S. (2009). Uncertainty in a cropping system model for predicting runoff and erosion on clay soils in southern Queensland. 18th World IMACS / MODSIM Congress, Cairns, Australia 13-17 July 2009.

Dougall, C. and Waters, D. (2013). Source Catchment's modelling of Great Barrier Reef Catchments: Better targeting through event based water quality and quantity assessment. MODSIM 2013, Adelaide, Australia.

DSITIA (2012). Land use summary 1999 - 2009: Great Barrier Reef catchments. Queensland Department of Science, Information Technology, Innovation and The Arts, Brisbane, Australia. 
Ellis, R. and Searle, R. (2013). An integrated water quality modelling framework for reporting on Great Barrier Reef catchments. MODSIM 2013, Adelaide, Australia.

Freebairn, D.M., Wockner, G.H., Hamilton, A.N., and Rowland, P. (2009). Impact of soil conditions on hydrology and water quality for a brown clay in the north eastern cereal zone of Australia. Australian Journal of Soil Research 47, 389-402.

Keating, B.A., Carberry, P.S., Hammer, G.L., Probert, M.E., Robertson, M.J., Holzworth, D., Huth, N.I., Hargreaves, J.N.G., Meinke, H., Hochman, Z., McLean, G., Verburg, K., Snow, V., Dimes, J.P., Silburn, M., Wang, E., Brown, S., Bristow, K.L., Asseng, S., Chapman, S., McCown, R.L., Freebairn, D.M., and Smith, C.J. (2003). An overview of APSIM, a model designed for farming systems simulation. European Journal of Agronomy 18, 267-288.

Kelley, P., and O’Brien, A. (Eds) (2012). Source Scientific Reference Guide, eWater Cooperative Research Centre, Canberra, Australia.

Littleboy, M., Silburn, D.M., Freebairn, D.M., Woodruff, D.R., Hammer, G.L., and Leslie, J.K. (1992). The impact of soil erosion on sustainability of production in cropping systems. I. Development and validation of a simulation model. Australian Journal of Soil Research 30, 757-774.

McKeon, G.M., Ash, A., Hall, W.B., and Stafford Smith, M. (2000). Simulation of grazing strategies for beef production in north-east Queensland. In 'Applications of Seasonal Climate Forecasting in Agricultural and Natural Ecosystems - the Australian Experience'. (Eds GL Hammer, N Nicholls, C Mitchell) pp. 227-252. (Kluwer Academic: The Netherlands).

Rattray, D.J., Freebairn, D.M., McClymont, D., Silburn, D.M., Owens, J., and Robinson, B. (2004). HOWLEAKY? The journey to demystifying 'simple' technology. Paper 422. In ISCO 2004 'Conserving Soil and Water for Society: Sharing Solutions', 13th International Soil Conservation Organisation Conference, Brisbane, July 2004. (eds SR Raine, AJW Biggs, NW Menzies, DM Freebairn, PE Tolmie).

Rickert, K.G., Stuth, J.W., and McKeon, G.M. (2000). Modelling pasture and animal production. In 'Field and Laboratory Methods for Grassland and Animal Production Research'. (Eds L 'tMannetje, RM Jones) pp.29-66. CABI publishing, New York.

Robinson, J.B., Shaw, M., Chamberlain, T., Searle, R., and Freebairn, D. (2012). A functional soil classification and associated soil parameter files for modelling the terrestrial water balance of the Great Barrier Reef catchments. Australian Soil Science Society Conference 2012: Soil solutions for diverse landscapes, Hobart, Tasmania.

Robinson, J.B., Shaw, M., Silburn, D.M., Roberts, A., Viagak, O., and McClymont, D. (2011). An improved model for linking Phosphorus loads in runoff to climate, soil and agricultural management. MODSIM 2011, Perth, Australia.

Robinson, J.B., Silburn, D.M., Rattray, D., Freebairn, D.M., Biggs, A.J.W, McClymont, D., and Christodoulou, N. (2010). Modelling shows that the high rates of deep drainage in parts of the Goondoola Basin in semi-arid Queensland can be reduced with changes to the farming systems. Australian Journal of Soil Research 48, 58-68.

Shaw, M., Silburn, D.M., Thornton, C., Robinson, B., and McClymont, D. (2011). Modelling pesticide runoff from paddocks in the Great Barrier Reef with HowLeaky. MODSIM 2011, Perth, Australia.

Thorburn, P.J., Biggs, J.S., Attard, S.J. and Kemei, J. (2011). Environmental impacts of irrigated sugarcane production: Nitrogen lost through runoff and leaching. Agriculture Ecosystems and Environment 144, 112.

Thorburn, P.J., Meier, E.A., and Probert, M.E. (2005). Modelling nitrogen dynamics in sugarcane systems: Recent advances and applications. Field Crops Research 92, 337-351.

Whish G. (Ed.) (2011). Land types of Queensland. Version 2.0. Prepared by the Grazing Land Management Workshop Team, Department of Employment, Economic Development and Innovation, Brisbane. PR073212.

Whish G. (2012). GRASP modelling of grazing systems in Great Barrier Reef catchments. Technical Report to Paddock to Reef Integrated Monitoring, Modelling and reporting program. Department of Agriculture, Fisheries and Forestry, Queensland, Australia. 